\title{
Adaptação respiratória neonatal: influência da inseminação artificial (IA) $x$ fertilização in vitro (FIV) nos parâmetros hemogasométricos e no comprimento de bezerros recém-nascidos da raça Holandesa Preta e Branca (HPB)
}

Gabriela Nascimento Dantas", Bianca Paola Santarosa, Vitor Hugo dos Santos, Maicon Vinicius Galdino, Fernando José Benesi, Roberto Calderon Gonçalves

Faculdade de Medicina Veterinária e Zootecnia, Universidade Estadual Paulista (UNESP), Botucatu, SP, Brasil

*Autor correspondente

e-mail: gabrielan.dantas@gmail.com

\section{Resumo}

O sucesso da adaptação neonatal está diretamente relacionado com estabelecimento de função respiratória que possibilite trocas gasosas eficientes. Bezerros originados por FIV podem apresentar problemas ao nascimento, como distocia e dificuldade respiratória. Devido ao alto valor genético e econômico, esses animais requerem do médico veterinário diagnóstico precoce e terapia eficaz em casos de má adaptação neonatal. 0 diagnóstico do neonato com hipóxia pode ser feito utilizando-se, além dos sinais clínicos, a hemogasometria. 0 objetivo deste trabalho foi comparar a influência do método de concepção (IA ou FIV) sobre a função pulmonar de recém-nascidos da espécie bovina, além de verificar a diferença de tamanho entre bezerros concebidos pelas duas diferentes técnicas. Foram utilizados 40 bezerros machos da raça HPB, sendo 20 oriundos de IA e 20 de FIV. 0 parto foi acompanhado e as colheitas de sangue provenientes da veia jugular foram realizadas com $0,6,12,24$ e 48 horas após o nascimento. Utilizou-se para a análise hemogasômetro portátil (I-STAT ${ }^{\circledR}$ Abbott Laboratories, Illinois, EUA) com cartuchos do tipo EG8+. As variáveis estudadas foram: pH, pressões de dióxido de carbono e oxigênio, excesso de bases, bicarbonato, saturação de oxigênio, cálcio, glicose, hematócrito e hemoglobina. 0 comprimento de coluna dos animais foi mensurado com auxílio de fita métrica e compreendeu a distância obtida entre a articulação atlanto-occipital até a primeira vértebra coccígea. Para a análise estatística, foi utilizado o teste de Wilcoxon-Mann-Whitney para amostras independentes. Houve diferença estatística $(\mathrm{P}<0,05)$ apenas no momento zero horas após o nascimento para a variável glicose, que foi maior nos bezerros FIV, e no momento 12 horas, onde os valores do cálcio foram menores no grupo FIV. As outras variáveis mantiveram-se dentro dos parâmetros estabelecidos pela literatura. Também houve diferença estatística para a variável comprimento de coluna, maior nos animais FIV. Assim, os animais FIV apresentaram maior tamanho, o que pode justificar dificuldades no parto e, em decorrência, sofrimento fetal e piores condições ao nascimento. No presente estudo, os partos foram 
acompanhados e, na ocorrência de distocia, forneceu-se ajuda obstétrica (6/20 animais IA precisaram de auxílio no parto e 14/20 no grupo FIV). Este fator pode ter influenciado positivamente nos parâmetros respiratórios destes animais. Além disso, a hiperglicemia mais acentuada no momento do nascimento no grupo FIV pode ser justificada por maior estresse no trabalho de parto. A observação de valores menores de cálcio no momento 12 horas do grupo FIV salienta a necessidade de monitoração destes animais para que seja instituída terapia de reposição precoce, evitando prejuízos para a saúde do animal. 0 acompanhamento do parto e o diagnóstico inicial da má adaptação neonatal são fundamentais para a instituição de condutas e terapias que visam a manutenção da saúde dos bezerros, diminuindo mortalidade e prejuízos econômicos. 